\title{
Home-Based, Moderate-Intensity Exercise Training Using a Metronome Improves the Breathing Pattern and Oxygen Saturation During Exercise in Patients With COPD
}

\author{
[AQ00] Eva Bernardi, MD; Luca Pomidori, PhD; Francesca Cassutti, MD; Annalisa Cogo, MD
}

\begin{abstract}
Purpose: One of the well-known but less-investigated effects of pulmonary rehabilitation in patients with chronic obstructive pulmonary disease (COPD) is the change in breathing pattern toward a more efficient one (higher tidal volume $\left[\mathrm{V}_{\mathrm{T}}\right]$, lower breathing frequency). Evidence suggests this change can be obtained only with supervised, high-intensity exercise training (ExTr). However, some patients either do not have such programs available or are unable to exercise at that intensity. We evaluated the effects of a 12-wk, moderate-intensity, home-monitored ExTr program using a metronome on the breathing pattern, oxygen saturation $\left(\mathrm{SpO}_{2}\right)$, and dyspnea during exercise in patients with COPD.

Methods: Twenty-one patients with COPD ( 7 female, aged 64-85 yr) performed spirometry, incremental, and endurance walking tests (at $60 \%$ of maximal walking speed) on a treadmill before and after training. During the endurance test, patients were equipped with an instrument that continuously monitored ventilation $\left(\dot{\mathrm{V}}_{\mathrm{E}}\right)$, breathing pattern, and $\mathrm{SpO}_{2}$. Patients trained at home for $12 \mathrm{wk}, 30 \mathrm{~min} / \mathrm{d}$ for at least $4 \mathrm{~d} / \mathrm{wk}$ at moderate intensity. A metronome paced the walking speed.

Results: Sixteen patients completed the program. After training, a significant change was observed in breathing pattern (lower $\dot{\mathrm{V}}_{\mathrm{E}}$ and $\dot{\mathrm{V}}_{\mathrm{E}} / \mathrm{V}_{\mathrm{T}}$ ratio; $\left.P<.001\right)$, a higher $\mathrm{SpO}_{2}(P<.001)$, and a lower dyspnea perception at the same work intensity $(P<$ $.01)$. The $\dot{\mathrm{V}}_{\mathrm{E}} / \mathrm{V}_{\mathrm{T}}$ ratio and $\mathrm{SpO}_{2}$ during exercise were significantly related $(r=0.56, P=.001)$.

Conclusion: A change in breathing pattern towards more efficient ventilation can be obtained with a moderate, home-monitored ExTr program with a pace that is controlled by a metronome. Decreased $\dot{\mathrm{V}}_{\mathrm{E}} / \mathrm{V}_{\mathrm{T}}$ was associated with an improved $\mathrm{SpO}_{2}$ during exercise.
\end{abstract}

Key Words: breathing pattern $\bullet$ COPD $\bullet$ exercise $\bullet$ home-based exercise

xertional dyspnea is one of the main factors limiting ex-

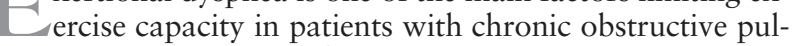
monary disease (COPD). ${ }^{1}$ Dyspnea in COPD is multifactorial; one of the main contributors is the ventilatory limitation, which increases the work of breathing. ${ }^{1}$ During exercise, the breathing pattern (relationship between minute ventilation $\left[\dot{\mathrm{V}}_{\mathrm{E}}\right]$ and tidal volume $\left[\mathrm{V}_{\mathrm{T}}\right]$ ) often changes toward more shallow breathing (higher breathing frequency [Bf] and smaller $\left[\mathrm{V}_{\mathrm{T}}\right]$ ), which is less efficient for gas exchange. This leads to

Author Affiliation: Biomedical Sport Studies Center, University of Ferrara, Italy.

All authors have read and approved the article.

The authors declare no conflicts of interest.

Correspondence: Eva Bernardi, MD, Biomedical Sport Studies Center, University of Ferrara, via Gramicia, 35, Ferrara, FE 44100, Italy (bernardi.eva@gmail.com).

Copyright (C) 2018 Wolters Kluwer Health, Inc. All rights reserved.

DOI: 10.1097/HCR.0000000000000360 oxygen desaturation ${ }^{1}$ and an increase in the ventilatory requirement, which is another cause of reduced performance in COPD. At a given $\dot{\mathrm{V}}_{\mathrm{E}}$, the $\mathrm{V}_{\mathrm{T}}$ is lower and the Bf higher in patients with COPD compared with healthy subjects. ${ }^{2}$

A breathing pattern characterized by a higher $\mathrm{V}_{\mathrm{T}}$ and lower $\mathrm{Bf}$ is more efficient for gas exchange by reducing the dead space, increasing alveolar ventilation, improving oxygen saturation $\left(\mathrm{SpO}_{2}\right)$, and minimizing the work of breathing. This fact has been shown both in healthy subjects exposed to altitude ${ }^{3}$ and in patients with chronic diseases such as $\mathrm{COPD}^{4}$ and heart failure. ${ }^{5}$ However, it should be noted that the adoption of a more efficient breathing pattern (higher $\mathrm{V}_{\mathrm{T}}$ and lower $\mathrm{Bf}$ ) is not easy to learn and maintain, especially during exercise.

Despite the importance of a more efficient breathing pattern to counteract the ventilatory limitation during exercise, few studies have analyzed which interventions are effective for improving the breathing pattern. Charususin et $\mathrm{al},{ }^{6}$ as well as our group, ${ }^{7}$ have shown that respiratory muscle training can improve breathing patterns during exercise in patients with COPD. Moreover, in 1997, Casaburi et $\mathrm{al}^{8}$ demonstrated that supervised, high-intensity (with a workload $\geq 70 \%$ of maximum workload) exercise training (ExTr) modified the breathing pattern toward one characterized by a higher $\mathrm{V}_{\mathrm{T}}$ and lower Bf during exercise in patients with COPD. These results have been confirmed in other studies. ${ }^{9-13}$ The same effect was not obtained with moderate-exercise training performed at home and based on the distance/time method. ${ }^{12,13}$ For these reasons, $\mathrm{Pu}-$ ente-Maestu et a ${ }^{12}$ suggested that there is a "dose-dependent effect" such that the greater improvement in the breathing pattern was obtained with a supervised and high-intensity ExTr. More recently, a review ${ }^{14}$ confirmed that patients with COPD who exercised under supervision at high intensity demonstrated the changes in ventilatory parameters that are associated with reduced dyspnea. However, those authors raised the question that not all patients can train at a high intensity that is uncomfortable and may discourage participation, especially at home without a caregiver that encourages the patient to train at the prescribed intensity. In addition, supervised ExTr, either in the hospital or in the outpatient clinic, is often difficult to follow for both economic and logistical reasons. These are crucial issues, as adequate exercise intensity, accessibility, and long-term adherence to the ExTr program are keys points for ensuring and maintaining benefits. To be successful, a strategy to increase physical activity in patients with COPD must be attractive and easily used during the daily routines of patients. One example is the use of devices that allow patients to maintain the rate of walking during a home-based ExTr program. We have previously demonstrated ${ }^{15}$ that the use of a metronome allows patients to maintain and sustain the optimal exercise intensity and improve exercise capacity during a home-based training program. The improvements were maintained for 12 mo. 
Based on these considerations, we aimed to assess the effect of a 12-wk, moderate-intensity, home-monitored ExTr using a metronome ExTr program on the breathing pattern, $\mathrm{SpO}_{2}$, and dyspnea during exercise in patients with COPD.

\section{PATIENTS AND METHODS}

Patients with COPD who attended the outpatient clinic of the Department of Respiratory Diseases, Ferrara University Hospital, were consecutively recruited. The Ethics Committee of the University of Ferrara approved the study and all patients provided written informed consent.

Patients were in stable condition, free from an exacerbation for at least $3 \mathrm{mo}$, and had not previously participated in the other ExTr program. Subjects were screened for cardiovascular, neurological, or musculoskeletal diseases, which could be exercise-limiting factors. All patients during the program followed their regular pharmacological treatment.

At baseline, all patients underwent spirometry and 2 walking tests on a treadmill (an incremental symptom-limited test and an endurance test). After warm-up, the incremental test was started at $1 \mathrm{~km} / \mathrm{hr}$ and the speed was progressively increased by $0.2 \mathrm{~km} / \mathrm{hr}$ every $10 \mathrm{~m}$. The test ended when the patient was unable to continue due to either severe dyspnea or muscular fatigue. The incremental test was used to define the maximal walking speed. After a 1-hr rest, patients performed a 6 -min endurance test at $60 \%$ of maximal walking speed. Intensity of dyspnea and leg discomfort were rated using the modified Borg scale (0-10) at rest, every minute during exercise, and at peak exercise. During the endurance test, patients used a portable spirometry system (Spiropalm, Cosmed) to measure $\dot{\mathrm{V}}_{\mathrm{E}}$ and breathing patterns (Bf, $\mathrm{V}_{\mathrm{T}}$, and $\dot{\mathrm{V}}_{\mathrm{E}} / \mathrm{V}_{\mathrm{T}}$ ratio) during exercise with continuous monitoring of $\mathrm{SpO}_{2}$ and heart rate.

The average speed recorded during the endurance test was chosen as the walking speed for the self-monitored

\section{Panel A}

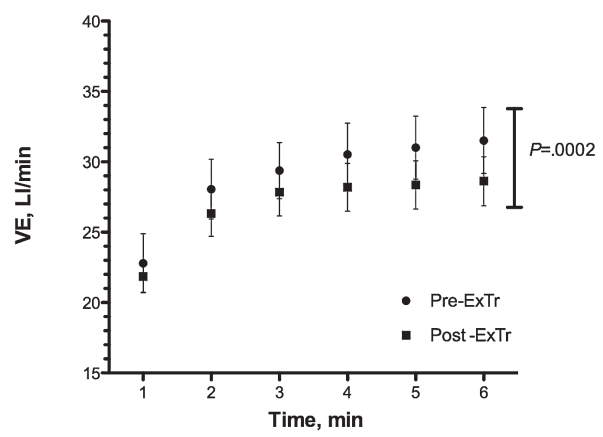

Panel C

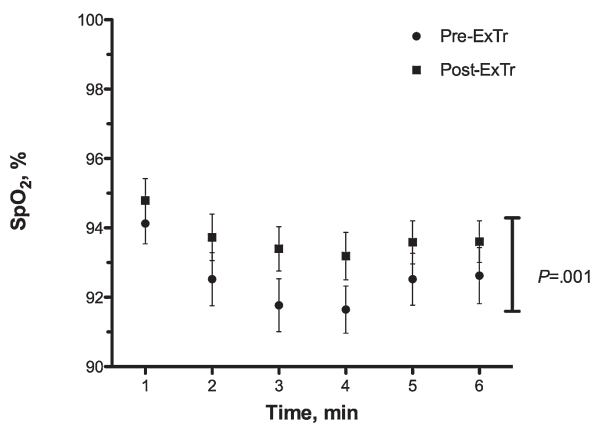

ExTr at home. After $1 \mathrm{wk}$, the endurance test was repeated to identify the optimal exercise intensity and familiarize the patients with the ExTr program. Patients were asked to walk at home $30 \mathrm{~min} / \mathrm{d}$ for at least $4 \mathrm{~d} / \mathrm{wk}$ and to complete a daily training diary to document their compliance with home-based training: session duration, dyspnea perception, and muscular fatigue were reported.

A light portable metronome (model DM50 clip-on metronome, Seiko) was used to maintain the prescribed walking speed. Special attention was given to the explanation of the home training method, especially in terms of walking speed and step frequency. The cadence of the metronome was regulated by observing the patients walking both on the treadmill at the designated speed and then in a corridor to ensure that the cadence was comfortable with the individual preferred step length. ${ }^{15}$ An exercise therapist supervised patients weekly for the first month to check that they maintained the correct step frequency. After $12 \mathrm{wk}$, patients repeated the spirometry and the endurance test at the same walking speed as the baseline test.

\section{STATISTICAL ANALYSIS}

Data are presented as mean $\pm \mathrm{SD}$. The $t$ test was used to compare anthropometric, spirometry, and endurance test data before and after the training. The effects of training on ventilation, breathing patterns, and $\mathrm{SpO}_{2}$ were evaluated by analysis of variance tests (data were averaged every minute) and the $P$ values were adjusted with Bonferroni correction. Pearson's $\rho$ correlation analysis was carried out to compare the $\dot{\mathrm{V}}_{\mathrm{F}} / \mathrm{VT}$ ratio (difference of $\dot{\mathrm{V}}_{\mathrm{F}} / \mathrm{V}_{\mathrm{T}}$ ratio during the test and at rest $)$ and delta $\mathrm{Spo}_{2}\left(\mathrm{SpO}_{2}\right.$ at rest - lower $\left.\mathrm{SpO}_{2}\right)$.

\section{RESULTS}

Twenty-one stable patients with COPD ( 7 female; 4 mild, 10 moderate, and 7 severe COPD) were included in the study.

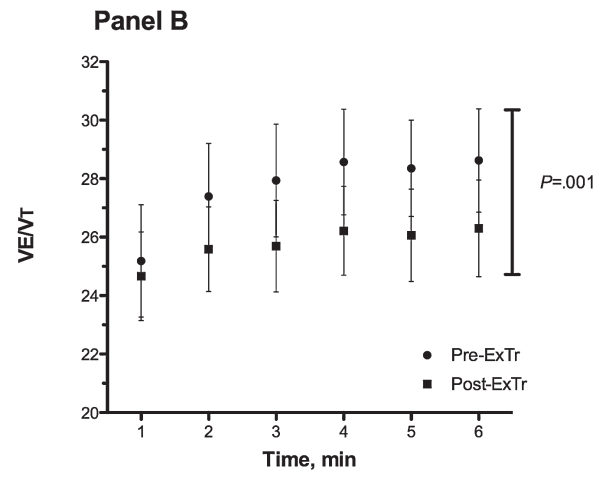

Figure 1. Ventilation $(\mathrm{A})$, ventilation/tidal volume ratio $(\dot{\mathrm{V}} \mathrm{E} N \mathrm{NT})(\mathrm{B})$, and oxygen saturation $\left(\mathrm{SpO}_{2}\right)(\mathrm{C})$ trends during the endurance test before and after the ExTr program. Data reported as mean values \pm SE at 1, 2, 3, 4, 5, and 6 min of the endurance test. Pre- and post-ExTr data were analyzed using analysis of variance. ExTr indicates exercise training; $\mathrm{SpO}_{2}$, oxygen saturation; $\dot{\mathrm{V}} \mathrm{E} \mathrm{NT}$, ratio between ventilation and tidal volume. 


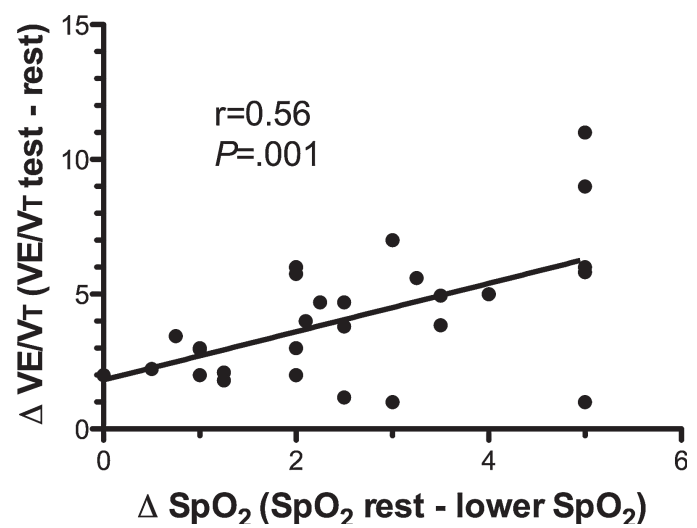

Figure 2. Correlation between the delta $(\Delta) \dot{V}_{E} N_{T}$ ratio $\left(\dot{V}_{E} N_{T}\right.$ ratio during the test - at rest) and the delta $\mathrm{Spo}_{2}\left(\mathrm{Spo}_{2}\right.$ at rest - lower $\left.\mathrm{Spo}_{2}\right)$ during the endurance test. $\mathrm{SpO}_{2}$ indicates oxygen saturation; $\dot{\mathrm{V}}_{\mathrm{E}} \mathrm{V}_{\mathrm{T}}$, ratio between ventilation and tidal volume.

The age range of the study population was 64 to $85 \mathrm{yr}$. Sixteen patients completed the study. Two patients dropped out of the study on their own volition due to poor compliance to exercise (reluctant to follow the prescribed program) and 3 dropped out for exacerbation of their COPD.

The diary analysis showed that all patients trained on average $31 \pm 8 \mathrm{~min}$ daily, $5 \pm 1 \mathrm{~d} / \mathrm{wk}$, with a dyspnea $5 \pm 1$ on the Borg scale (0-10). Compared with baseline, subjects showed no changes in spirometry parameters after training (forced expiratory volume in the first second $=65 \% \pm$ $11 \%$ vs $65 \% \pm 12 \%$ predicted).

After training, a significantly lower $\dot{\mathrm{V}}_{\mathrm{E}}$ and $\dot{\mathrm{V}}_{\mathrm{E}} / \mathrm{V}_{\mathrm{T}}$ ratio was found during the endurance test (Figures $1 \mathrm{~A}$ and $1 \mathrm{~B}$ ). We observed a higher $\mathrm{SpO}_{2}$ during exercise (mean $\mathrm{SpO}_{2} 92 \%$ $\pm 2 \%$ vs $94 \% \pm 2 \% ; P<.001$; Figure $1 \mathrm{C})$. Patients also reported significantly lower dyspnea ( $6 \pm 1$ vs $4 \pm 2$ on the 0 -10 Borg scale; $P<.01$ ) and muscular fatigue perception $(5 \pm 2$ vs $2 \pm 2$ on the $0-10$ Borg scale; $P<.01$ ) at the end of the test. A significant correlation between the change in $\dot{\mathrm{V}}_{\mathrm{E}} / \mathrm{V}_{\mathrm{T}}$ ratio and the change in $\mathrm{SpO}_{2}$ during exercise $(r=$ $0.56, P=.001$ ) was found (Figure 2 ).

\section{DISCUSSION}

The main result of this preliminary study was the effectiveness of a home-monitored (using a metronome) ExTr program at moderate intensity for changing the breathing pattern toward a more efficient one (ie, higher $\mathrm{V}_{\mathrm{T}}$ and lower Bf) and is associated with an increased $\mathrm{SpO}_{2}$ during exercise. In fact, after training, we found a lower ventilation and a decreased $\dot{V}_{\mathrm{E}} / \mathrm{V}_{\mathrm{T}}$ ratio (an index of the greater contribution of $\mathrm{V}_{\mathrm{T}}$ to $\mathrm{V}_{\mathrm{E}}$ ). The decreased $\dot{\mathrm{V}}_{\mathrm{E}} / \mathrm{V}_{\mathrm{T}}$ ratio influenced gas exchange. Patients showed a higher oxygen saturation during exercise, which correlated with the decreased $\dot{V}_{\mathrm{E}} / \mathrm{V}_{\mathrm{T}}$. These results are consistent with previous studies. ${ }^{3-5}$

It seems that the use of a metronome to drive the intensity of training allows patients to achieve and maintain over time the appropriate exercise intensity, ${ }^{15}$ provided that the step length and frequency are properly checked. It is possible that when the ExTr is based on the distance/time method, the walking speed progressively decreases due to the difficulty of maintaining the prescribed intensity, thus making the program less effective. ${ }^{13}$ In fact, the traditional methods of prescribing a home-based ExTr program involve the use of different devices (ie, pedometers or accelerometers) that monitor the amount of physical activity but not the intensity of the exercise. Therefore, we can conclude that the positive effects on the breathing pattern can also be achieved using a nonsupervised ExTr program at moderate intensity. However, the key point is the adoption of strategies that allow patients to maintain over time the prescribed exercise intensity. As expected, we also found that the decreased $\dot{\mathrm{V}}_{\mathrm{E}} / \mathrm{V}_{\mathrm{T}}$ ratio and the higher $\mathrm{SpO}_{2}$ during exercise, at the same work intensity, reduced the perception of dyspnea.

While these are preliminary data, it is encouraging that significant improvements are reported. The main limitation of this study was the lack of a control group, but further recruitment of patients is underway to confirm these results using a randomized controlled study design.

\section{REFERENCES}

1. O'Donnell DE. Ventilatory limitations in chronic obstructive pulmonary disease. Med Sci Sports Exerc. 2000;S647-S655.

2. Palange P, Ward SA, Carlsen KH, et al. Recommendations on the use of exercise testing in clinical practice. Eur Respir J. 2007;29(1):185-209.

3. Bernardi L, Passino C, Spadacini G, et al. Reduced hypoxic ventilatory response with preserved blood oxygenation in yoga trainees and Himalayan Buddhist monks at altitude: evidence of a different adaptive strategy? Eur J Appl Physiol. 2007;99(5):511-518.

4. Pomidori L, Campigotto F, Amatya TM, Bernardi L, Cogo A. Efficacy and tolerability of yoga breathing in patients with chronic obstructive pulmonary disease: a pilot study. J Cardiopulm Rehabil Prev. 2009;29(2):133-137.

5. Bernardi L, Spadacini G, Bellwon J, Hajric R, Roskamm H, Frey AW. Effect of breathing rate on oxygen saturation and exercise performance in chronic heart failure. Lancet. 1998;351: 1308-1311.

6. Charususin N, Gosselink R, McConnell A, Demeyer H, Topalovic M, Decramer M, Langer DInspiratory muscle training improves breathing pattern during exercise in COPD patients. Eur Respir J. 2016;47(4):1261-1264.

7. Bernardi E, Pomidori L, Bassal F, Contoli M, Cogo A. Respiratory muscle training with normocapnic hyperpnea improves ventilatory pattern and thoracoabdominal coordination, and reduces oxygen desaturation during endurance exercise testing in COPD patients. Int J Chron Obstruct Pulmon Dis. 2015;10:1899-1906.

8. Casaburi R, Porszasz J, Burns M, Carithers ER, Chang RS, Cooper CB. Physiologic benefits of exercise training in rehabilitation of patients with severe chronic obstructive pulmonary disease. Am J Respir Crit Care Med. 1997;155:1541-1551.

9. O’Donnell DE, McGuire M, Samis L, Webb KA. General exercise training improves ventilatory and peripheral muscle strength and endurance in chronic airflow limitation. Am J Respir Crit Care Med. 1998;157(5, pt 1):1489-1497.

10. Puente-Maestu L, Abad YM, Pedraza F, Sánchez G, Stringer WW. A controlled trial of the effects of leg training on breathing pattern and dynamic hyperinflation in severe COPD. Lung. 2006;184(3):159-167.

11. Georgiadou O, Vogiatzis I, Stratakos G, et al. Effects of rehabilitation on chest wall volume regulation during exercise in COPD patients. Eur Respir J. 2007;29(2):284-291.

12. Puente-Maestu L, Sánz ML, Sánz P, Ruiz de Ona JM, Rodriguez-Hermosa JL, Whipp BJ. Effect of two types of training on pulmonary and cardiac responses to moderate exercise in patients with COPD. Eur Respir J. 2000;15(6):1026-1032.

13. Puente-Maestu L, Sánz ML, Sánz P, Cubillo JM, Mayol J, Casaburi R. Comparison of effects of supervised versus self-monitored training programmes in patients with chronic obstructive pulmonary disease. Eur Respir J. 2000;15(3):517-525.

14. Osterling K, MacFadyen K, Gilbert R, Dechman G. The effects of high intensity exercise during pulmonary rehabilitation on ventilatory parameters in people with moderate to severe stable COPD: a systematic review. Int J Chron Obstruct Pulmon Dis. 2014;9:1069-1078.

15. Pomidori L, Contoli M, Mandolesi G, Cogo A. A simple method for home exercise training in patients with chronic obstructive pulmonary disease. J Cardiopulm Rehabil Prev. 2012;32(1):53-57. 


\section{AUTHOR QUERY}

TITLE: Home-Based, Moderate-Intensity Exercise Training Using a Metronome Improves the Breathing Pattern and Oxygen Saturation During Exercise in Patients With COPD

AUTHORS: Eva Bernardi, Luca Pomidori, Francesca Cassutti, and Annalisa Cogo

[AQ00]: Please check if authors name are correctly captured for given names (in red) and surnames (in blue) for indexing after publication. 